\title{
POLÍTICAS PÚBLICAS VOLTADAS PARA A INCLUSÃO ESCOLAR: CONTRIBUIÇÕES DA IMPLEMENTAÇÃO DO CURSO DE LETRAS LIBRAS NA UFRA
}

\author{
WANÚBYA DO NASCIMENTO MORAES CAMPELO (UFRA) ${ }^{1}$ \\ LILIANE AFONSO DE OLIVEIRA (UFRA) ${ }^{2}$ \\ SÍLVIO AUGUSTO DE OLIVEIRA HOLANDA (UFPA) ${ }^{3}$
}

\begin{abstract}
RESUMO: Neste trabalho há debates sobre as contribuições das políticas públicas criadas para surdos no Brasil e o seu percurso desde a Constituição Federal (1988), a Lei de Diretrizes e Bases da Educação Nacional (LDBEN), a Lei no 10.436, a Lei no 10.098, o Decreto no 5.626 até o Plano Nacional de Educação. Assim, discutir-se-ão suas implicações na Educação Inclusiva brasileira, no que concerne à criação e expansão de cursos de nível superior de Licenciatura em Língua Brasileira de Sinais (LIBRAS) pelas Instituições de Ensino Superior (IES), como a implementação deste curso na Universidade Federal Rural da Amazônia (UFRA), no curso extensivo e no intensivo do Plano Nacional de Professores da Educação Básica (PARFOR). Neste diapasão, o estudo constituiu-se em uma pesquisa de campo, de caráter descritivo, desenvolvida por meio de um estudo de caso com cinco participantes que atuam como docentes na UFRA. Os dados foram coletados por meio da realização de entrevistas, com roteiro semiestruturado, nas quais se averiguaram as seguintes problemáticas: Qual o conhecimento sobre a legislação que ampara os PCDs, especificamente, o surdo? E qual a contribuição da implementação do Curso de Letras Libras na UFRA? A pesquisa compreende aspectos teóricos e práticos da Educação Superior, tais como, processos formativos inclusivos, com base em Quadros (2003) e Skliar (2001). Os resultados demonstram que os docentes ainda não têm amplo conhecimento da legislação da educação brasileira para alunos surdos. Contudo, eles reconheceram a importância da implementação de um curso para a formação de professores preparados para a educação de surdos, favorecendo a inclusão escolar.
\end{abstract}

PALAVRAS-CHAVE: Políticas. Surdos. Libras. UFRA.

ABSTRACT: In this work there are debates about the contributions of public policies created for the deaf in Brazil and their path since the Federal Constitution (1988), the Law of Guidelines and Bases of National Education (LDBEN), Law no 10.436, Law no 10.098, Decree $n^{\circ} 5.626$ up to the National Education Plan. Thus, its implications for Brazilian Inclusive Education will be discussed, with regard to the creation and expansion of undergraduate courses in Brazilian Sign Language (LIBRAS) by Higher Education Institutions (HEIs), as the implementation of this course at the Federal Rural University of the Amazon (UFRA), in the extensive and intensive course of the National Plan for Teachers of Basic Education (PARFOR). In this tuning fork, the study consisted of a field research, of a descriptive character, developed through a case study with five participants who act as teachers at UFRA. The data were collected through interviews, with a semi-structured script, in which the following problems were investigated: What is the knowledge about the legislation that supports the PCDs, specifically, the deaf? And what is the contribution of implementing the Libras Literature Course at UFRA? The research comprises theoretical and practical aspects of Higher Education, such as inclusive training processes, based on Quadros (2003) and Skliar (2001). The results demonstrate that teachers still do not have a wide knowledge of the Brazilian education legislation for deaf students. However, they recognized the importance of implementing a course for the training of teachers prepared for the education of the deaf, favoring school inclusion.

KEYWORDS: Politics. Deaf. Libras. UFRA.

\footnotetext{
${ }^{1}$ Docente da Universidade Federal Rural da Amazônia (UFRA), Doutoranda do Programa de Pós-Graduação em Letras da Universidade Federal do Pará (UFPA). wanubyacampelo@gmail.com.

2 Docente da Universidade Federal Rural da Amazônia (UFRA), Doutoranda do Programa de Pós-Graduação em Comunicação, Linguagens e Cultura da Universidade da Amazônia (UNAMA), liliane_afonso@yahoo.com.br.

${ }^{3}$ Docente da Universidade Federal do Pará (UFPA), Doutor em Letras pela Universidade de São Paulo (USP), eellip@hotmail.com.
}

Revista Trama | Volume 16 | Número 37 | Ano 2020 | p. 60-70 | e-ISSN 1981-4674 


\section{$=$ TRAMA $=$}

\section{INTRODUÇÃO}

O estudo das políticas inclusivas implementadas no Brasil desde sua Constituição Federal (1988) é uma temática relevante que carece de análises e acompanhamentos, visando verificar indicativos para sua melhor compreensão e aprimoramento.

Em relação aos direitos da pessoa surda, a base legal brasileira progride no reconhecimento à especificidade linguística desses cidadãos, conforme se observa nas leis $n^{\circ}$ 10.172 de 2001 e no 10.436 de 2002, e nos Decretos n²296 de 2004 e no 5626 de 2005.

Neste diapasão, a presente pesquisa procurou investigar o processo de implementação do Curso de Letras Libras da Universidade Federal Rural da Amazônia (UFRA), na cidade de Belém, no estado do Pará. No bojo das discussões sobre as Políticas de Inclusão brasileira, propôs-se a seguinte problemática: Qual o conhecimento dos professores do Instituto Ciberespacial (ICIBE), ao qual o curso de Letras Libras dessa universidade está atrelado, sobre a legislação que ampara os alunos portadores de deficiência, especificamente, o surdo? E qual a contribuição da implementação do curso de Letras Libras na UFRA?

Levou-se em consideração que o curso de Licenciatura em Letras Libras da UFRA foi ofertado pela primeira vez em 2016, com três turmas: uma, de ensino extensivo, no ICIBE e outras duas, na modalidade intensiva, sendo uma na capital do estado, Belém, e outra no interior, na cidade de Tomé-açu, pelo Programa de Formação de Professores da Educação Básica (PARFOR). Torna-se, assim, relevante delimitar a referida instituição de ensino superior e seu curso inovador na área de educação especial como lócus da investigação.

A modalidade de ensino intensiva ofertada pelo PARFOR ocorre durante as férias escolares, com aulas presenciais intensivas para docentes da rede pública de educação básica em exercício que precisam de formação em áreas específicas e estejam cadastrados na Plataforma Freire pelas Secretarias de Educação da Rede. Já na modalidade extensiva os alunos são selecionados por meio das notas obtidas pelo Exame Nacional do Ensino Médio (ENEM), na qual são ofertadas 40 (quarenta) vagas para entrada anual.

Determinou-se como objetivo geral da pesquisa: compreender e analisar aspectos teóricos e práticos dos processos formativos inclusivos na Educação Superior, observando a UFRA. E como objetivos específicos: a. Elucidar as principais políticas públicas brasileiras que se voltam para a Educação inclusiva; b. Identificar se os participantes da pesquisa possuíam conhecimento prévio sobre a base legal da educação inclusiva, especialmente sobre o surdo; c. Analisar as percepções que docentes tiveram sobre a implementação de um curso de LIBRAS em uma Universidade de caráter rural, como a UFRA e os saberes vivenciados/ construídos neste processo de relação com sujeitos surdos; $d$. Verificar se os sujeitos apontam intenção de aprender a Língua Brasileira de Sinais (Libras) para comunicar-se com os alunos e professores surdos da Instituição.

\section{METODOLOGIA}

A presente investigação decorre de uma pesquisa descritiva, de campo, de abordagem qualitativa, constituindo-se de um estudo de caso. Os participantes da pesquisa são 04 docentes da UFRA, sendo que três já atuaram no curso intensivo e extensivo e um que atuou apenas no curso intensivo. Foram entrevistados dois indivíduos do sexo masculino e dois do sexo feminino.

Os entrevistados foram devidamente esclarecidos sobre os objetivos e metodologia da pesquisa. Após os esclarecimentos, os entrevistados assinaram o Termo de Consentimento Livre e Esclarecido, onde manifestam seu interesse em participar da pesquisa. Dessa forma, 


\section{$=$ TRAMA $=$}

eles tiveram também assegurados os direitos de sigilo de identidade e de voluntariado na pesquisa, e foram identificados no corpus como $A, B, C$ e D, sendo $A$ uma docente surda do sexo feminino; $B$, um docente ouvinte do sexo feminino; $C$, um docente surdo do sexo masculino; e $\mathrm{D}$, docente ouvinte do sexo masculino.

Em relação ao procedimento metodológico, adotou-se inicialmente a realização do levantamento bibliográfico sobre a base legal da educação inclusiva, a saber, a Constituição Federal (1988), a Lei no 9.394, de 1996 (LDBEN), a Lei no 10.436, a Lei no 10.098, o Decreto n ${ }^{0} 5.626$, de 2005, até o Plano Nacional de Educação, ademais do aprofundamento de autores como Quadros (2003; 2005), Skliar (2001), dentre outros teóricos que abordam temas como: educação inclusiva e educação de surdos.

Na produção dos dados realizaram-se entrevistas semiestruturadas e levantamento documental junto à UFRA, referente ao Projeto Político Pedagógico do Curso de Licenciatura em Letras Libras, a fim de identificar a trajetória de implementação do curso, além do Plano de Desenvolvimento Institucional da UFRA, no qual observou-se a inserção do Curso de Letras Libras na instituição.

A sistematização e a análise de dados foram realizadas diante das seguintes categorias de análise: Educação Inclusiva, Inclusão Escolar, Políticas Públicas, Educação Bilíngue e Libras.

Em seus 50 anos de existência, a UFRA, lócus desta pesquisa, destaca-se na Amazônia por ter prestado relevantes serviços à região amazônica, em especial à formação de milhares de profissionais em Ciências Agrárias, incluindo estrangeiros de mais de 15 países.

A UFRA é constituída por quatro Institutos Temáticos, que são as unidades responsáveis pela execução do ensino, da pesquisa e da extensão e tem caráter inter, multi e transdisciplinar em áreas do conhecimento. São eles: a) Instituto de Ciências Agrárias (ICA); b) Instituto de Saúde e Produção Animal (ISPA); c) Instituto Socioambiental e dos Recursos Hídricos (ISARH), e d) Instituto Ciberespacial (ICIBE).

Os institutos da UFRA são constituídos por docentes, técnico-administrativos e discentes que neles exercem suas atividades. Cada um dos Institutos citados atua em funções relacionadas a seus campos do saber e compartilham entre si o objetivo de ensino, pesquisa e extensão. Além da Sede, em Belém, capital do estado do Pará, a UFRA tem 5 campi no interior do Estado.

\section{A EDUCAÇÃO NA CONSTITUIÇÃO FEDERAL}

Dispõe o capítulo III da seção I da Constituição Federal de 1988 que a educação é direito de todos e dever do Estado, que deve proporcionar os meios de atendimento educacional especializado, preferencialmente na rede regular de ensino, aos que são considerados portadores de deficiência na forma da lei.

De fato, todos são iguais perante a lei, nesse sentido, impróprio seria considerar que isonomia é tratar todos da mesma forma. As pessoas não são iguais, elas se diferenciam por sexo, raça, nível de escolaridade, renda e tantas outras características que transformam cada ser humano um espécime único no seu meio social.

Observando essas desigualdades e visando proteger aqueles grupos que são considerados o elo mais frágil da sociedade - grupos como idosos, crianças e pessoas com deficiência -, o Estado discrimina direitos que irão possibilitar a equidade genérica desses indivíduos. Para atender às necessidades específicas de pessoas com deficiência, não basta que o Estado garanta sua vaga na rede pública e gratuita de ensino para que as políticas públicas em educação sejam concretas, é necessário, antes de tudo, que ele promova meios 


\section{$=$ TRAMA $=$}

de inclusão que permitam o real acesso dessas pessoas aos diferentes níveis de escolaridade. Isto é, são necessários recursos que incluem desde rampas de acesso a cadeirantes, banheiros adaptados, professores especializados em línguas de sinais e tantas outras medidas técnicas e pedagógicas.

A Constituição Federal, como exposto acima, pouco desenvolve a temática: não estabelece programas de ação, não trata dos diferentes tipos de deficiências existentes e não define bases curriculares, deixando a cargo da legislação infraconstitucional a responsabilidade de esmiuçar de que forma a educação especial inclusiva deve ocorrer.

\section{A EDUCAÇÃO ESPECIAL NA LEI BRASILEIRA DE DIRETRIZES E BASES DA EDUCAÇÃO}

A LDB, Lei Brasileira de Diretrizes e Bases da Educação Nacional (Lei n 9.394, de 20 de dezembro de 1996) em seu Caput entende por Educação Especial a modalidade de educação escolar oferecida preferencialmente na rede regular de ensino, para alunos com deficiência.

No primeiro parágrafo do Artigo 58, a Lei decreta que haverá, quando necessário, serviços de apoio especializado na escola regular, para atender aos alunos com necessidades especiais, já no segundo parágrafo, a lei afirma que o atendimento será feito em classes especiais, sempre que, em função das condições específicas dos alunos, não for possível a sua integração nas classes regulares de ensino.

No artigo 59, inciso I a Lei assegura aos educandos currículos, métodos, técnicas, recursos educativos e organização específicos para atender às suas necessidades. No que concerne aos docentes, o inciso III afirma que aos discentes são garantidos professores com especialização adequada para atendimento especializado e que eles também propiciem a integração desses alunos nas classes comuns.

Apesar de a LDB ser bem abrangente em relação à educação inclusiva, entretanto ela não menciona o caso da Educação para surdos, aliás, a lei não aborda nomeadamente nenhum caso de deficiência e nem aponta alternativas para as suas necessidades específicas, como um intérprete de Libras para alunos surdos.

\section{LEI No 10.436, UMA ESPERANÇA PARA EDUCAÇÃO DOS SURDOS}

A legislação ordinária é demasiadamente sucinta em relação à educação especial de surdos, por exemplo, a lei no 10.436/2002 - composta por apenas por cinco artigos sobre a Língua Brasileira de Sinais - Libras. Nela, há o reconhecimento das Libras como meio legal de comunicação e expressão e a sua caracterização como um sistema linguístico de natureza visual-motora de comunidades surdas do Brasil cuja estrutura gramatical é própria.

O artigo $4^{\circ}$ informa a inclusão da disciplina da Língua Brasileira de Sinais - Libras nos currículos de formação dos cursos de Educação Especial, Fonoaudiologia e Magistério, Nível Médio e Superior. Nesse sentido, a lei alterou os Parâmetros Curriculares Nacionais (PCNs) dos supracitados cursos, uma forma de obrigar que os novos professores e fonoaudiólogos graduandos das universidades ingressassem no mercado de trabalho mais preparados para o convívio com esses sujeitos surdos e suas particularidades.

Assim, embora lacônica, a lei significou um grande avanço para comunidade surda que pela primeira vez obteve do Estado garantias que a inclusão de alunos surdos poderia ter um acompanhamento mais especializado dentro das salas de aula. Como objetivo de regulamentar e dar maior aplicabilidade à supracitada lei seguiu-se o Decreto 5.626, de 22 de dezembro de 


\section{$=$ TRAMA $=$}

2005 que propõe algumas ações que privilegiam a inclusão social e reafirma a Libras como dialeto linguístico nacional próprio dos surdos.

A lei e o decreto são frutos de uma luta constante de movimentos de surdos, uma vez que as políticas linguísticas do Brasil sempre promoveram o Português escrito e oral, deixando à margem todas as outras línguas existentes, como as línguas indígenas (Tupi, macuxi, xavante...), as línguas das populações imigrantes e/ou de fronteira (Alemão, italiano, espanhol...) e a língua de sinais.

Dentro desse diagnóstico de exclusão sociolinguístico, os estudiosos das línguas apontam o espaço escolar como sendo o ambiente onde mais ocorre esse tipo de repressão cultural (QUADROS; PATERNO, 2006). Mediante isso, criou-se um debate para desestimular o caráter monolíngue imposto ao Brasil e que atribuem um preconceito sobre todas as línguas que se desviam do padrão nacional oficial.

Obviamente, não basta que a Lei reconheça a Libras como língua oficial dos surdos para que a norma tenha plena eficácia e aplicabilidade, serão necessários profissionais qualificados e espaços próprios e discussões mais profundas acerca das questões que envolvem a problemática, inclusive envolvendo a participação dos surdos como principais sujeitos ativos participantes.

Num quadro em que a língua portuguesa oral e escrita toma status de língua superior e a Libras, por sua vez, um mero meio de comunicação para aqueles que não conseguem desenvolver a fala, o surdo é cada vez mais excluído do processo de integração social, sofrendo por não conseguir interagir e ser compreendido pela coletividade. Muitos acabam até por criar certo tipo de repulsa pelo português, uma espécie de defesa contra a diminuição de sua língua materna. Não obstante, a prática se torna altruísta, pois exclui os surdos do rico conhecimento literário, legislativo e científico (etc.) da língua nacional.

Desse modo, o legislador ordinário, ao confirmar a Libras como língua oficial dos surdos, compreende a predileção destes pela comunicação através da língua de sinais e atenua o conflito entre a Libras e o Português.

O ideal não é segmentar as diversidades linguísticas, mas desenvolvê-las na escola de forma a fomentar o bilinguismo ou plurilinguismo, para ampliar assim o leque de conhecimento a ser construído.

O Decreto regulamenta ainda a criação de cursos superiores de Letras-Libras e Pedagogia bilíngue - Libras, além de incluir disciplinas relacionadas nos desenhos curriculares de outras graduações visando à formação de profissionais capacitados para atuar nos três níveis de educação. De acordo com essa proposta, surge o Curso de Licenciatura em Letras Libras da UFRA.

\section{LEI No 10.098, DE 19 DE DEZEMBRO DE 2000}

A Lei $n^{0} 10.098$, estabelece normas gerais e critérios básicos para a promoção da acessibilidade das pessoas portadoras de deficiência ou com mobilidade reduzida, mediante a supressão de barreiras e de obstáculos nas vias e espaços públicos, no mobiliário urbano, na construção e reforma de edifícios e nos meios de transporte e de comunicação.

Em seu artigo 18, contempla, especificamente, o caso dos surdos ao implementar a formação de profissionais intérpretes de escrita em braile, linguagem de sinais e de guiasintérpretes, para facilitar qualquer tipo de comunicação direta à pessoa portadora de deficiência sensorial e com dificuldade de comunicação. 


\section{$=$ TRAMA $=$}

\section{PLANO NACIONAL DOS DIREITOS DA PESSOA COM DEFICIÊNCIA}

O Plano Nacional dos Direitos da Pessoa com Deficiência - Viver sem Limite, por meio do Decreto 7.612, de 17 de novembro de 2011, ressalta o compromisso do Brasil com as prerrogativas da Convenção da ONU sobre os Direitos das Pessoas com Deficiência.

De acordo com a proposta do Viver sem Limite, essa Convenção deve acontecer na vida das pessoas, por meio da articulação de políticas governamentais de acesso à educação, inclusão social, atenção à saúde e acessibilidade.

O Plano ressalta o compromisso do Brasil sobre os Direitos das Pessoas com Deficiência, em que aduz o acesso à educação é direito de todos, sem discriminação, em igualdade de oportunidades.

O plano Viver sem Limite investe em recursos e serviços de apoio à educação básica, como ações que contemplam implantação de Salas de Recursos Multifuncionais, promoção de acessibilidade nas escolas, formação de professores para o Atendimento Educacional Especializado, aquisição de ônibus escolares acessíveis e ampliação do Programa Benefício de Prestação Continuada da Assistência Social (BPC) na Escola.

Em termos de educação profissional, agora pessoas com deficiência têm prioridade na matrícula nos cursos do Programa Nacional de Acesso ao Ensino Técnico e Emprego (Pronatec).

Nas IFES, estão sendo instalados núcleos de acessibilidade e ofertados cursos de Letras/Libras e de formação em Pedagogia na perspectiva bilíngue (Libras/Língua Portuguesa).

A inclusão social é almejada não só pelas Pessoas com Deficiência, mas por todo indivíduo que se sente excluído de alguma forma, do convívio social, uma vez que os Surdos são indivíduos com uma cultura, língua e identidade próprias.

\section{DOCENTES E A EXPANSÃO UNIVERSITÁRIA, O DESAFIO DO CURSO DE LICENCIATURA EM LETRAS/ LIBRAS DA UFRA}

A UFRA existe como Universidade há 13 anos e, desde a época que ainda era a Faculdade de Ciências Agrárias do Pará - FCAP, pouco havia sido feito efetivamente no que diz respeito à acessibilidade e à inclusão de pessoas com deficiência ou com necessidades específicas. Assim, a necessidade de aprofundar estudos e desenvolver ações relacionadas à acessibilidade e à inclusão levou, em 2010, um grupo de professores a pensar ações que fomentassem as discussões sobre o acesso irrestrito e a inclusão das pessoas com deficiência não somente nos campi da UFRA, mas em toda a sociedade, sobretudo na região Amazônica.

Os cidadãos que requerem consideração especial não podem ficar excluídos dos benefícios da sociedade e, por outro lado, é necessário estabelecer condições para que o desenvolvimento desta sociedade contribua inequivocamente para melhorar as condições de vida e de bem-estar daqueles cidadãos.

Em fevereiro de 2012, foi aprovado por unanimidade no CONSUN da UFRA o Núcleo Amazônico de Acessibilidade, Inclusão e Tecnologia (ACESSAR) como mais uma Unidade da UFRA ligada à reitoria que tem como principal objetivo desenvolver ações multidisciplinares que promovam o acesso irrestrito, a facilidade de uso e a democratização do conhecimento com vistas à inclusão das pessoas com deficiência.

Em 2012, a UFRA, por meio do Núcleo ACESSAR, começou a receber recursos do programa Incluir para Acessibilizar a Instituição. Em junho de 2012, recebeu ofício do MEC para que manifestasse interesse em ofertar cursos de graduação em Letras/Libras. Na ocasião, por 


\section{$=$ TRAMA $=$}

meio do Núcleo Amazônico de Acessibilidade, Inclusão e Tecnologia (ACESSAR), foi apresentado ao MEC uma proposta e uma carta de intenção da UFRA manifestando interesse em ofertar o curso de graduação em Letras/Libras.

No dia 03 de agosto de 2012, foi enviada novamente ao MEC uma carta intenção e proposta de implantação do curso para apreciação. No final de agosto do mesmo ano, a UFRA teve parecer favorável e foi aprovada a oferta do curso. Em seguida, a Universidade discutiu internamente a criação do curso e teve sua aprovação por meio da Resolução n 99/2013CONSUN/UFRA e da Resolução n 194/2014- CONSEPE/UFRA, que aprovaram a criação do curso no campus sede.

Inicia-se, então, um trabalho na Universidade com o intuito de contratar professores e construir um prédio, financiado pelo Programa Viver sem Limites, para sua instalação. Tais fatos provocaram um atraso na oferta da primeira turma, a princípio prevista para o ano letivo de 2014. Também não foi possível iniciar em 2015, em decorrência da falta de recursos financeiros para realizar um processo seletivo específico.

Somente no final de 2015, após avaliação da PROEN, resolveu-se realizar o processo seletivo a partir do Exame Nacional do Ensino Médio (ENEM), com garantia de reserva de vaga para pessoas surdas (Resolução $n^{\circ}$ 285/2015-CONSEPE-UFRA), para afiançar o cumprimento da proposta do curso e do Decreto n ${ }^{0} 5.626 / 2005$. Desta forma, em janeiro de 2016, houve seleção entre os candidatos inscritos no ENEM 2015 para a constituição da primeira turma do curso de Licenciatura em Letras/Libras da UFRA, que iniciou no primeiro semestre letivo de 2016.

Neste ano de 2016, então, pela primeira vez a UFRA ofertou o Curso de Letras/Libras. Vale ressaltar que, historicamente a IFES tem um caráter agrário. Sendo assim, este é um curso pioneiro na Educação Especial na Instituição.

Atualmente o Curso de Letras/Libras estrutura-se com carga horária de 3.388h, apoiada na LDB 9394/1996 e na Resolução CNE/CP nº 001/06.

Ao analisarmos a inclusão do Curso de Letras/Libras no contexto de uma Universidade prioritariamente agrária, os docentes apontaram que a principal contribuição deste curso para o contexto Institucional foi o esclarecimento sobre as peculiaridades da Libras e a sua relevância no contato com os surdos, os quais têm o direito de ter acesso à educação com acessibilidade comunicacional. Em virtude disso, podemos considerar que essa implementação apresenta uma concepção socioantropológica da surdez (SKLIAR, 2001), configurando-a enquanto diferença e não como inferioridade.

Os docentes A, B, C e D quando inquiridos sobre o conhecimento referente à legislação que ampara os alunos com necessidades especiais, especificamente o surdo, contribuíram que:

O meu conhecimento é mais específico, ou seja, é o mais estudado e o mais discutido, o Decreto 5626 em que regulamenta a Lei 24/04/2002 é a lei da Libras. Então o meu conhecimento é aqui. O Decreto tem uma série de direito dos surdos, primeiro linguístico, de acessibilidade dentro da escola, dentro da sociedade, dentro do hospital e também na formação do professor, do médico terapeuta, na formação do tradutor interprete para o exercício. Então o meu conhecimento específico do surdo e o principal é a formação bilíngue que ensino e a aprendizagem sejam voltados para base linguística seja a primeira língua do surdo que é a Libras (DOCENTE A, 2019).

Conhecimento sim por lei a gente tem, a Lei 10436 de 24 de abril de 2002 que considera a Língua brasileira de sinais como sendo um meio legal de expressão é que traz o direito que a criança surda tem de ser matriculada em uma escola comum junto com as outras crianças que tem o convívio, que justamente essa lei 


\section{$=$ TRAMA $=$}

vem trazer a questão da inclusão de não separação de enxergar esse surdo como uma pessoa a princípio tenha só um meio de comunicação diferenciado do nosso que não é nossa língua, mas é a Língua Brasileira de Sinais. E a da importância fundamental que se trabalha desde 2002. Além disso, também outro decreto trata sobre a questão de fazer disciplina e trabalhar a inclusão de Libras como disciplina curricular nos cursos de licenciatura e tanto nos outros cursos obrigatório que é os cursos de literatura que trata a formação do professor e para os demais cursos que não sejam licenciatura, mas estarem dentro do currículo para serem oferecidos como qualquer outra veterinário, floresta, os alunos que formam nos outros cursos para terem a possibilidade de fazer uma formação nessa língua é até fundamental porque primeiro formação do formador que está se preparando para entrar na sala de aula com os alunos para tratar com os alunos e as outras pessoas que estão se formando em outras áreas que não é de formação, mas que vão conviver possivelmente com pessoas que são surdas, então é fundamental isso (DOCENTE B, 2019).

Existe a Lei 10436, além disso o Decreto 5626. Nós temos a Lei de acessibilidade não me recordo o número. Sim, eu sou de acordo com as leis vigentes. Enquanto a lei 10436 ela é a base por exemplo da inserção do surdo em empresas, no mercado de trabalho, na saúde e na educação. O Decreto 5626 é uma legislação mais aprofundada que descreve por exemplo a questão dos intérpretes de libras, o direito a educação e a saúde, a questão do português para enfim diversas situações que são direitos dos surdos que então esse Decreto vem regulamentar a Lei (DOCENTE C, 2019).

Eu sei que essa legislação existe hoje em dia para que eles sejam amparados legalmente e, as instituições de ensino superior, eu acredito que também médio e, fundamental, possam atender a esses alunos mesmo que até mesmo não queiram eu sei que elas existem é o meu conhecimento, é bem pouco em relação a que legislação são essas qual é o ano e o que elas dizem (DOCENTE D, 2019).

Os docentes corroboraram que reconhecem que há uma legislação que ampara os alunos com necessidades especiais, especificamente o surdo, citando inclusive algumas Leis e Decretos. Percebeu-se que os docentes A, B e C, provavelmente por estarem mais tempo em contato com os cursos intensivo e extensivo de Letras Libras da UFRA e B e C, por serem surdos, apresentam mais propriedades nos discursos acerca de quais as legislações existentes para o surdo. O entrevistado D demonstrou, de início, ter convicção acerca do conhecimento das legislações. No entanto, quando da sua continuidade discursiva, não apresenta domínio das legislações. O docente D, na UFRA, atuou apenas na modalidade de ensino intensiva do curso de Letras Libras, ofertada para as turmas do PARFOR.

No questionamento sobre qual a contribuição da implementação do Curso de Letras Libras na UFRA os participantes da pesquisa afirmaram que:

A contribuição que a UFRA tem é formando futuro profissionais para o exercício do ensino da Libras na escola, na universidade ou em qualquer lugar. Então nós sabemos que hoje o problema principal do surdo na sociedade não é o Ser SURDO. Não. É a falta de comunicação e a falta de acessibilidade linguística. Então a UFRA, tem o papel muito importante porque está contribuindo para sociedade, para inclusão e inserção do surdo dentro da sociedade linguística, formando futuros profissionais para o exercício. E assim efetivar de fato a cidadania desse sujeito surdo que hoje atualmente a gente encontra excluídos (DOCENTE A, 2019).

Ela vem justamente trazer a possibilidade de formação pensando no curso em si, na formação de pessoas que se formam no curso de Letra/Libras para tratar e fazer a formação de outros formadores para inserir dentro de sala de aula e buscar e ampliar dentro das escolas que hoje nós temos como foi colocado aqui que a Letras Libras como uma língua, onde as crianças surdas vão conviver com outras Revista Trama | Volume 16 | Número 37 | Ano 2020 | p. 60-70 | e-ISSN 1981-4674 
crianças, então a necessidade dentro do estado e município da falta de profissionais da área para tratar desse assunto que a demanda é muito grande e, então com a relação a essa questão, de fundamental do curso de Libras dentro da UFRA, além do mais provocar a instituição a fazer a sua própria mudança porque a entrada do curso de Letras Libras dentro da UFRA já é um marco para essa instituição que uma instituição que tem um cunho muito agrário que vem sendo inserido cursos na área de formação do professor que vem trazendo questão das áreas das humanas e esse curso. Ele trata muito disso e ele tem uma singularidade do lado humano muito grande, então ele vem provocar mudanças extremamente significativas dentro da instituição e contribuir para a formação de pessoas, profissionais para atuarem no estado, no município, no Brasil e assim por diante (DOCENTE B, 2019).

Então esse curso tem a importância muito grande porque ele possibilita a formação linguística e as outras áreas que nela está incorporada por exemplo os estudos descritivos fonéticos, fonológicos em relação a língua de sinais, isso possibilita que as pessoas de fato compreendam que língua é essa. Então Curso de Letras/Libras é claro que tem uma importância muito grande na UFRA, é importante para surdos e ouvintes no sentindo dessa formação linguística focada nessa língua que é a Libras (DOCENTE C, 2019).

Acho que essa implementação é fundamental ela garante uma visibilidade a esse público tanto a necessidade de formação do profissional qualificado quanto ao atendimento futuro que essa população vai entrar nas instituições de ensino então ela vai ter profissionais qualificados para saber lidar, saber interagir e tornar o processo educativo mais facilitado (DOCENTE D, 2019).

Neste sentido, os docentes A e C mencionaram que a UFRA tem papel importante na implementação do Curso de Letras Libras dentro da instituição, uma vez que contribui para formar profissionais para o exercício do ensino da Libras na escola, na universidade ou em qualquer lugar. Os docentes A e C corroboram com a necessidade de as pessoas, ouvintes e surdas, de fato compreenderem a Libras como uma língua, com suas perspectivas descritivas, sintáticas, fonéticas e fonológicas efetivando, assim, a identidade e a cidadania desse sujeito surdo que, atualmente ainda está excluso na sociedade.

A docente $B$ concentra sua fala na necessidade do Estado e dos municípios garantirem esses profissionais na Rede e apresenta a implementação do Curso de Letras Libras como um marco histórico na instituição, que visa a contribuir para atender essa demanda de profissionais nos municípios, apresentando a singularidade do curso de provocar mudanças extremamente significativas dentro e fora da instituição na formação de pessoas.

O docente $D$ afirmou que a implementação do Curso de Letras Libras na Ufra é fundamental pois garante uma visibilidade aos surdos, sublimando a necessidade de formação de profissionais qualificados que irão saber lidar, interagir e tornar o processo educativo mais facilitado.

Destarte, os docentes corroboram que o amparo legal torna o ambiente educacional, na possibilidade de um local mais acessivel a todos, fato que muitos citaram não ser factível sem a obrigatoriedade das leis.

Os docentes ouvintes relatam que o contato com as pessoas surdas do Curso de Letras/Libras provocou um desconforto, a priori, pela dificuldade de comunicação, mas gerou um respeito à diferença e à Identidade surda.

A professora e pesquisadora da Universidade Federal de Santa Catarina, Ronice Muller Quadros, percebe que há um conflito entre a Libras e o Português no processo educacional dos surdos, por conta, justamente das políticas linguísticas brasileiras: 


\title{
$=$ TRAMA $=$
}

O conflito entre Libras e o Português na educação dos surdos é reflexo das políticas linguísticas do Brasil. Este é um país plurilíngue onde há muitas línguas indígenas, línguas de imigrantes e duas línguas de sinais registradas. Entretanto, a política linguística brasileira ainda é pautada na crença de que o país seja monolíngue, favorecendo a língua portuguesa em detrimento das tantas outras línguas existentes (QUADROS, 2005, p. 27).

A autora aponta em seus estudos que os surdos querem ter a Libras como a sua língua de instrução, sua língua para se comunicar com o mundo, interagindo e compreendendo os demais também através de seus sinais e não por meio de uma imposição da língua portuguesa, como acontece muitas das vezes.

Dessa forma, os docentes apontaram que apesar dos entraves enfrentados em relação à implementação da política educacional inclusiva, a conquista do acesso à educação irá demandar uma urgência em modificações estruturais, organizacionais e pedagógicas da Instituição.

\section{CONSIDERAÇÕES FINAIS}

De acordo com as leis brasileiras, pessoas com as mais distintas necessidades especiais deveriam ser atendidas pelo Estado, no que concerne às suas especificidades; assim, cada especialidade teria o seu atendimento feito por um profissional adequado, em um ambiente propício e com a estrutura adequada.

Entretanto, percebemos que essa multiplicidade em sua maioria, não é atendida de forma adequada. No caso dos surdos, entendemos uma idealização institucional de um status bilíngue para os surdos. Na verdade, alguns não tem o domínio da Libras, ou tem a sua aquisição tardia. Os surdos almejam aprender Libras como sua primeira língua L1, contudo, principalmente os surdos filhos de ouvintes não tem esse contato desde o início de sua alfabetização, por falta de conhecimento dos pais.

Nesta discussão bilíngue, a professora Ronice Quadros faz a seguinte colocação:

\begin{abstract}
Diante de uma política de subtração linguística aplicada aos surdos em que o português deveria ser a única língua a ser adquirida, os surdos negam esta língua por ter representado por muitos anos uma ameaça ao uso da língua de sinais. Essa realidade implica processos de delimitação de fronteiras e poderes. Os surdos têm razão em assumir uma postura defensiva diante do português, uma vez que esta língua foi tida (ainda é tida) como a língua melhor, a língua oficial, a língua superior em oposição à língua de sinais brasileira representada como uma opção, como um instrumento utilizado apenas caso o aluno surdo não tenha conseguido acessar a língua (QUADROS, 2005, p. 29).
\end{abstract}

Logo, a Libras ainda é colocada às margens da aprendizagem, em detrimento do que alguns docentes entendem como a verdadeira língua nativa, o português. Assim, percebemos que, se nas propostas das políticas públicas temos um direcionamento bilíngue, em sua implementação factual, ainda esbarramos em algumas resistências, pois, ao que parece, esse direcionamento visa a garantir que o português continue sendo a língua principal de acesso ao conhecimento.

Nesse sentido, percebemos que as políticas públicas brasileiras vêm avançando em relação às necessidades dos indivíduos surdos, como no caso da implementação do Curso de Licenciatura em Letras/Libras da UFRA. Os participantes desta pesquisa reconheceram a importância da implementação de um curso para a formação de professores preparados para a educação de surdos, favorecendo com isso a inclusão escolar do sujeito surdo, mas afirmam 


\section{$=\mathrm{T} R A M A=$}

que ainda há a necessidade de aprofundamento em relação à acessibilização comunicacional destes sujeitos para a efetivação desta proposta bilíngue na Universidade.

\section{REFERÊNCIAS}

BRASIL. [Constituição (1988)]. Constituição da República Federativa do Brasil de 1988. Brasília, DF: Presidência da República, 1988. Disponível em: http://www.planalto.gov.br/ccivil_03/constituicao/ constituicao.htm. Acesso em: 14 dez. 2019

BRASIL. Decreto $n^{0}$ 7.612, de 17 de novembro de 2011. Institui o Plano Nacional dos Direitos da Pessoa com Deficiência - Plano Viver sem Limite. Diário Oficial [da] União: seção 1, Brasília, DF, ano 148, n. 221-A, p. 12, 18 nov. 2011.

BRASIL. Decreto n 5.296 , de 2 de dezembro de 2004. Regulamenta as leis nos 10.048, de 8 de novembro de 2000, que dá prioridade de atendimento às pessoas que especifica, e 10.098, de 19 de dezembro de 2000, que estabelece normas gerais e critérios básicos para a promoção da acessibilidade das pessoas portadoras de deficiência ou com mobilidade reduzida, e dá outras providências. Diário Oficial [da] União: seção 1, Brasília, DF, ano 141, n. 232, p. 5-10, 3 dez. 2004.

BRASIL. Decreto no 5.626, de 22 de dezembro de 2005. Regulamenta a Lei no 10.436, de 24 de abril de 2002, que dispõe sobre a Língua Brasileira de Sinais - LIBRAS, e o art. 18 da lei no 10.098, de 19 de dezembro de 2000. Diário Oficial [da] União: seção 1, Brasília, DF, ano 142, n. 246, p. 28-30, 23 dez. 2005. BRASIL. Lei no 9.394, de 20 de dezembro de 1996. Estabelece as diretrizes e bases da educação nacionaL. Diário Oficial [da] União: seção 1, Brasília, DF, ano 134, n. 248, p. 27833-27841, 23 dez. 1996.

BRASIL. Lei no 10.098, de 19 de dezembro de 2000. Estabelece normas gerais e critérios básicos para a promoção da acessibilidade das pessoas portadoras de deficiência ou com mobilidade reduzida, e dá outras providências. Diário Oficial [da] União: seção 1, Brasília, DF, ano 138, n. 244-E, p. 2-3, 20 dez. 2000. BRASIL. Lei no 10.172, de 9 de Janeiro de 2001. Aprova o Plano Nacional de Educação e dá outras providências. Diário Oficial [da] União: seção 1, Brasília, DF, ano 139, n. 7-E, p. 1, 10 jan. 2001. BRASIL. Lei no 10.436, de 24 de abril de 2002. Dispõe sobre a Língua Brasileira de Sinais - LíBRAS e dá outras providências. Diário Oficial [da] União: seção 1, Brasília, DF, ano 139, n. 79, p. 23, 25 abr. 2002. BRASIL. Lei no 13.005, de 25 de junho de 2014. Aprova o Plano Nacional de Educação - PNE e dá outras providências. Diário Oficial [da] União: seção 1, Brasília, DF, ano 151, n. 120, p. 1, 26 jun. 2014.

BRASIL. Ministério da Educação. Conselho Nacional de Educação. Conselho Pleno. Resolução CNE/CP n 1, de 15 de maio de 2006. Institui Diretrizes Curriculares Nacionais para o Curso de Graduação em Pedagogia, licenciatura. Brasília, DF: Presidência da República, 2006. Disponível em:

http://portal.mec.gov.br/cne/arquivos/pdf/rcp01_06.pdf. Acesso em: 11 nov. 2019.

DEFICIÊNCIA, Viver sem Limite - Plano Nacional dos Direitos da Pessoa com / Secretaria de Direitos Humanos da Presidência da República (SDH/PR) / Secretaria Nacional de Promoção dos Direitos da Pessoa com Deficiência (SNPD), VIVER SEM LIMITE - Plano Nacional dos Direitos da Pessoa com Deficiência: SDHPR/SNPD, 2013.

QUADROS, Ronice Muller de. O 'bi' em bilinguismo na educação de surdos. In: FERNANDES, Eulalia (org.). Surdez e bilinguismo. Porto Alegre: Mediação, 2005. p. 26-36.

QUADROS, Ronice Muller de; PATERNO, Uéslei. Políticas linguísticas: o impacto do Decreto 5.626 para os surdos brasileiros. Revista Espaço: Informativo Técnico-Científico do INES, Rio de Janeiro, n. 25/26, p. 19-25, jan./dez. 2006.

QUADROS, Ronice Muller de. Situando as diferenças implicadas na educação desurdos: inclusão/exclusão. Ponto de Vista: Revista de Educação e Processos Inclusivos, Florianópolis, n. 5, p. 81-111, 2003. SKLIAR, Carlos (org.). A surdez: um olhar sobre as diferenças. 2. ed. Porto Alegre: Mediação, 2001. p. 7-32. UNIVERSIDADE FEDERAL RURAL DA AMAZÔNIA. Conselho de Ensino, Pesquisa e Extensão. Resolução n¹94, de 17 de junho de 2014. Aprova a criação do Curso de Letras-LIBRAS do Campus Belém. Belém: UFRA, 2014.

UNIVERSIDADE FEDERAL RURAL DA AMAZÔNIA. Conselho de Ensino, Pesquisa e Extensão. Resolução $n^{\circ}$ 285, de 19 de novembro de 2015. Aprova a reserva de vagas para pessoas surdas no Curso de Letras/Libras na Universidade Federal Rural da Amazônia. Belém: UFRA, 2015.

UNIVERSIDADE FEDERAL RURAL DA AMAZÔNIA. Conselho Universitário. Resolução n 99, de 02 de dezembro de 2013. Aprova "Ad Referendum" a criação do Curso de Libras do Campus Belém. Belém: UFRA, 2013. 